\title{
Heart Rate and Extracellular Sodium and Potassium Modulation of Gap Junction Mediated Conduction in Guinea Pigs
}

\begin{abstract}
Michael Entz II, 2, Sharon A. George ${ }^{1,2}$, Michael J. Zeitz ${ }^{2}$, Tristan Raisch ${ }^{2,3}$, James W. Smyth ${ }^{2,4}$ and Steven Poelzing ${ }^{1,2,4 *}$
\end{abstract}

${ }^{1}$ Department of Biomedical Engineering and Mechanics, Virginia Polytechnic Institute and State University, Blacksburg, VA, USA, ${ }^{2}$ Virginia Tech Carilion Research Institute and Center for Heart and Regenerative Medicine, Virginia Polytechnic Institute and State University, Roanoke, VA, USA, ${ }^{3}$ Translational Biology, Medicine, and Health, Virginia Polytechnic Institute and State University, Blacksburg, VA, USA, ${ }^{4}$ Department of Biological Sciences, College of Science, Virginia Polytechnic Institute and State University, Blacksburg, VA, USA

Background: Recent studies suggested that cardiac conduction in murine hearts with narrow perinexi and 50\% reduced connexin43 (Cx43) expression is more sensitive to relatively physiological changes of extracellular potassium $\left(\left[\mathrm{K}^{+}\right]_{0}\right)$ and sodium $\left(\left[\mathrm{Na}^{+}\right]_{0}\right)$.

OPEN ACCESS

Edited by:

Gaetano Santulli,

Federico II University, Italy

Reviewed by:

Fadi G. Akar,

Icahn School of Medicine at Mount

Sinai, USA

Irena Levitan

University of Illinois at Chicago, USA

Tobias Opthof,

Academic Medical Center,

Netherlands

*Correspondence:

Steven Poelzing

poelzing@vtc.vt.edu

Specialty section:

This article was submitted to

Cardiac Electrophysiology,

a section of the journal

Frontiers in Physiology

Received: 23 October 2015

Accepted: 12 January 2016

Published: 02 February 2016

Citation:

Entz M II, George SA, Zeitz MJ, Raisch T, Smyth JW and Poelzing S (2016) Heart Rate and Extracellular

Sodium and Potassium Modulation of Gap Junction Mediated Conduction in

Guinea Pigs. Front. Physiol. 7:16.

doi: 10.3389/fphys.2016.00016
Purpose: Determine whether similar $\left[\mathrm{K}^{+}\right]_{\mathrm{o}}$ and $\left[\mathrm{Na}^{+}\right]_{\mathrm{o}}$ changes alter conduction velocity (CV) sensitivity to pharmacologic gap junction (GJ) uncoupling in guinea pigs.

Methods: $\left[\mathrm{K}^{+}\right]_{\mathrm{o}}$ and $\left[\mathrm{Na}^{+}\right]_{0}$ were varied in Langendorff perfused guinea pig ventricles (Solution $\mathrm{A}:\left[\mathrm{K}^{+}\right]_{\mathrm{o}}=4.56$ and $\left[\mathrm{Na}^{+}\right]_{\mathrm{o}}=153.3 \mathrm{mM}$. Solution $\mathrm{B}:\left[\mathrm{K}^{+}\right]_{\mathrm{O}}=6.95$ and $\left[\mathrm{Na}^{+}\right]_{\circ}=145.5 \mathrm{mM}$ ). Gap junctions were inhibited with carbenoxolone (CBX) (15 and $30 \mu \mathrm{M})$. Epicardial CV was quantified by optical mapping. Perinexal width was measured with transmission electron microscopy. Total and phosphorylated Cx43 were evaluated by western blotting.

Results: Solution composition did not alter CV under control conditions or with $15 \mu \mathrm{M}$ CBX. Decreasing the basic cycle length (BCL) of pacing from 300 to $160 \mathrm{~ms}$ decreased $\mathrm{CV}$ uniformly with both solutions. At $30 \mu \mathrm{M}$ CBX, a change in solution did not alter $\mathrm{CV}$ either longitudinally or transversely at $\mathrm{BCL}=300 \mathrm{~ms}$. However, reducing $\mathrm{BCL}$ to 160 ms caused CV to decrease more in hearts perfused with Solution B than A. Solution composition did not alter perinexal width, nor did it change total or phosphorylated serine 368 Cx43 expression. These data suggest that the solution dependent CV changes were independent of altered perinexal width or GJ coupling. Action potential duration was always shorter in hearts perfused with Solution B than A, independent of pacing rate and/or CBX concentration.

Conclusions: Increased heart rate and GJ uncoupling can unmask small CV differences caused by changing $\left[\mathrm{K}^{+}\right]_{0}$ and $\left[\mathrm{Na}^{+}\right]_{0}$. These data suggest that modulating extracellular ionic composition may be a novel anti-arrhythmic target in diseases with abnormal GJ coupling, particularly when heart rate cannot be controlled.

Keywords: electrophysiology, cardiac conduction, ephaptic coupling, gap junction 


\section{INTRODUCTION}

Normal cardiac conduction is critical for maintaining efficient pumping of the heart, and abnormal conduction can lead to arrhythmias and sudden cardiac death. Cardiac conduction is dependent on propagation of electrical signals from cellto-cell. Cell membrane depolarization can occur by raising the intracellular potential via direct axial current through high resistance gap junctions (gap junctional coupling), or by decreasing the extracellular potential between closely adjacent cells (ephaptic coupling) (Kucera et al., 2002; Sperelakis and McConnell, 2002; Mori et al., 2008; Veeraraghavan et al., 2012 , 2014). The concept of ephaptic coupling (EpC) is an old theory that has received renewed interest recently. While considered controversial in the cardiac field, $\mathrm{EpC}$ is more widely accepted in neurology (Bokil et al., 2001; Anastassiou et al., 2011; Su et al., 2012; Van der Goes van Naters, 2013; Maïna et al., 2015) and has even been proposed to be important for uterine contraction (Young, 2007). An elegant review by Nicholas Sperelakis and Keith McConnell in 2002 summarizes 6 possible mechanisms for EpC (Sperelakis and McConnell, 2002). Despite the many proposed mechanisms, the most prominent computational descriptions of $\mathrm{EpC}$ are electric field coupling (Rohr et al., 1998; Sperelakis and McConnell, 2002; Lin and Keener, 2010), or a combination of electric field coupling and the alteration of ionic concentrations within restricted extracellular microdomains (Mori et al., 2008; Hand and Peskin, 2010; Lin and Keener, 2010, 2013, 2014). Importantly, EpC is a theoretical parallel pathway to gap junction (GJ) mediated cell-to-cell electrical coupling.

Recent evidence in guinea pig ventricular myocardium (Veeraraghavan et al., 2012) demonstrates that inducing acute interstitial edema can increases intercellular separation within the perinexal intercalated disc microdomain and slow cardiac conduction by mechanisms consistent with mathematical predictions of EpC (Lin and Keener, 2010, 2013, 2014). Further, increasing perinexal width hypersensitizes myocardial conduction to pharmacologic GJ uncoupling (Veeraraghavan et al., 2012) and sodium channel inhibition (Veeraraghavan et al., 2015). This hypersensitivity is also consistent with computational predictions of EpC. Importantly, the corollary statement is that narrowing intercellular separation within the perinexus should decrease conduction sensitivity to GJ uncoupling and sodium channel inhibition.

In mice, we previously demonstrated that the relationships between cardiac conduction and GJs, perinexal width, and extracellular concentrations of sodium $\left(\left[\mathrm{Na}^{+}\right]_{\mathrm{o}}\right)$ and potassium $\left(\left[\mathrm{K}^{+}\right]_{\mathrm{o}}\right)$ are complex (George et al., 2015). Since it has also been shown that a change in $\left[\mathrm{K}^{+}\right]_{\mathrm{o}}$ from 5 to $8 \mathrm{mM}$ increased $\mathrm{CV}$ in guinea pig hearts (Kagiyama et al., 1982; Buchanan et al., 1985), one would expect a similar increase in mice. However, in mouse hearts with the native compliment of $\mathrm{Cx} 43$ (wild type), and wide perinexi $(>15 \mathrm{~nm})$, cardiac conduction was reduced when $\left[\mathrm{K}^{+}\right]_{\mathrm{o}}$ was raised from 4.6 to $6.1 \mathrm{mM}$ and concurrently $\left[\mathrm{Na}^{+}\right]_{\mathrm{o}}$ was decreased from 155 to $147 \mathrm{mM}$. More intriguing was the finding that the wild type hearts were insensitive to the same changes of $\left[\mathrm{K}^{+}\right]_{0}$ and $\left[\mathrm{Na}^{+}\right]_{0}$ when perinexal width was reduced. However, when Cx43 was reduced by 50\%, hearts with narrow perinexi perfused with a solution containing the higher $\left[\mathrm{K}^{+}\right]_{\mathrm{o}}$ and lower $\left[\mathrm{Na}^{+}\right]_{\mathrm{o}}$ had slower conduction relative to the solution with lower $\left[\mathrm{K}^{+}\right]_{\mathrm{o}}$ and higher $\left[\mathrm{Na}^{+}\right]_{0}$. Therefore, the width of the perinexus has important effects on modulating cardiac conduction sensitivity to alterations in $\left[\mathrm{K}^{+}\right]_{\mathrm{O}}$ and $\left[\mathrm{Na}^{+}\right]_{\mathrm{o}}$, and these effects are unmasked by GJ uncoupling.

Importantly, the relationship between conduction and perinexal width does not appear to be species dependent as similar findings were observed in guinea pig (Veeraraghavan et al., 2015). However, it remains unknown whether small extracellular changes in $\left[\mathrm{K}^{+}\right]_{\mathrm{O}}$ and $\left[\mathrm{Na}^{+}\right]_{\mathrm{o}}$ can alter conduction sensitivity to pharmacologic GJ coupling in guinea pig.

The purpose of this study was twofold. First, we wanted to determine if the observed response of cardiac conduction to $\left[\mathrm{K}^{+}\right]_{\mathrm{o}}$ and $\left[\mathrm{Na}^{+}\right]_{\mathrm{o}}$ is similar in normal guinea pig hearts as was observed in $\mathrm{Cx} 43$ wild type mouse hearts with narrow perinexi. Second, we sought to demonstrate that pharmacologically uncoupling GJs with a non-specific GJ uncoupler like carbenoxolone (CBX) would unmask conduction sensitivity to $\left[\mathrm{K}^{+}\right]_{\mathrm{o}}$ and $\left[\mathrm{Na}^{+}\right]_{\mathrm{o}}$ in guinea pig hearts with narrow perinexi.

\section{MATERIALS AND METHODS}

This study abides by and follows all guidelines set forth by the Institutional Animal Care and Use Committee at Virginia Polytechnic Institute and State University and NIH Guide for the Care and Usage of Laboratory Animals.

\section{Langendorff Perfusion}

Male retired breeder Hartley albino guinea pigs (Hilltop, Scottdale, PA, $N=28,800-1200 \mathrm{~g}, 12-19$ months old) were anesthetized using sodium pentobarbital [Nembutal, $30 \mathrm{mg} / \mathrm{kg}$ IP]. The heart was extracted, retrogradely perfused in a Langendorff perfusion apparatus and the atria excised to reduce competitive stimulation. The hearts were perfused with constant flow to maintain pressure between 40 and $55 \mathrm{~mm} \mathrm{Hg}$. Tyrode's solutions were altered as described in Table 1. The laboratory's historical Tyrode's composition in Table $\mathbf{1}$ is presented as a point of reference for the modified solutions used in these experiments.

Since "normal" plasma ion concentrations are species specific (UoM, 2009), we calculated a percentage change of $\left[\mathrm{K}^{+}\right]_{\mathrm{o}}$ and $\left[\mathrm{Na}^{+}\right]_{0}$ from the lowest values used in our previous mouse study (George et al., 2015). Thus, $\left[\mathrm{K}^{+}\right]_{\mathrm{o}}$ was changed in this study by $52 \%(4.56-6.95 \mathrm{mM})$ and $\left[\mathrm{Na}^{+}\right]_{\mathrm{o}}$ by $5.4 \%(145.5$ to $153.3 \mathrm{mM})$ from historic guinea pig Tyrode's solutions (Veeraraghavan et al., 2012). By this method, we designed Solutions A and B as noted in Table 1.

Solutions were perfused at $37^{\circ} \mathrm{C}, \mathrm{pH}$ 7.4. In each experiment, historic laboratory Tyrode's solution without the gap junction uncoupler $\mathrm{CBX}$ was perfused for $30 \mathrm{~min}$ at the beginning of the experiment, and then Solutions A and B were perfused for $10 \mathrm{~min}$ in a random order without CBX. This was followed by CBX (15 and $30 \mu \mathrm{M}$ ) in Solution A or B.

All conduction measurements were taken $10 \mathrm{~min}$ after the new perfusate reached the heart to control for the amount of 
TABLE 1 | Modified Tyrode's solution compositions (mM).

\begin{tabular}{lccc}
\hline & Historical & Solution A & Solution B \\
\hline GP Tyrode's solution & (mmol/L) & & \\
$\mathrm{NaCl}$ & 140 & 147.8 & 140 \\
$\mathrm{NaOH}$ & 5.5 & 5.5 & 5.5 \\
Total $\left[\mathrm{Na}^{+}\right]$ & $\mathbf{1 4 5 . 5}$ & $\mathbf{1 5 3 . 3}$ & $\mathbf{1 4 5 . 5}$ \\
$\mathrm{KCl}$ & 4.56 & 4.56 & 6.95 \\
Total $\left.^{[+} \mathbf{K}^{+}\right]$ & $\mathbf{4 . 5 6}$ & $\mathbf{4 . 5 6}$ & $\mathbf{6 . 9 5}$ \\
$\mathrm{CaCl}_{2}$ & 1.25 & 1.25 & 1.25 \\
$\mathrm{Dextrose}$ & 5.5 & 5.5 & 5.5 \\
$\mathrm{MgCl}_{2}$ & 0.7 & 0.7 & 0.7 \\
$\mathrm{HEPES}$ & 10 & 10 & 10 \\
$\mathrm{BDM}$ & 7.5 & 7.5 & 7.5 \\
\hline
\end{tabular}

time each heart was exposed to the solution, and because we previously demonstrated CBX slowed conduction to near steadystate values within 10 min (Veeraraghavan et al., 2015). Hearts were paced from the anterior left ventricular (LV) epicardium with a unipolar $\mathrm{AgCl}$ wire at basic cycle lengths (BCL) of 300 and $160 \mathrm{~ms}$ with a $5 \mathrm{~ms}$ pulse at 1.5 times pacing threshold (Veeraraghavan et al., 2013). A baseline BCL of $300 \mathrm{~ms}$ was chosen to mimic physiological resting guinea pig heart rate, while $160 \mathrm{~ms}$ BCL has been shown to decrease CV (Girouard et al., 1996; Akar et al., 2000; Lou et al., 2012).

\section{Transmission Electron Microscopy}

Left ventricular tissue from each intervention reported (3 hearts per intervention, 3 samples per heart) was sectioned into $1 \mathrm{~mm}^{3}$ cubes. The sections were fixed in $2.5 \%$ glutaraldehyde at $4^{\circ} \mathrm{C}$ overnight and then transferred to PBS at $4^{\circ} \mathrm{C}$. The tissue was processed as previously described (George et al., 2015). Images were collected using a transmission electron microscope (JEOL JEM1400) at 150,000 X magnification. Measurements were obtained using ImageJ (NIH) from 15 perinexi per sample. Total number of perinexi measured was 135 .

\section{Optical Mapping}

The voltage sensitive dye di-4-ANEPPS $(15 \mu \mathrm{M})$ was perfused for $10 \mathrm{~min}$ before the start of the experimental protocol. Cardiac motion was reduced with 2,3-butanedione monoxime (BDM, $7.5 \mathrm{mM}$ ). Hearts were further stabilized by applying light pressure on the posterior surface of the heart.

The dye was excited with a halogen light source (MHAB$150 \mathrm{~W}$, Moritex Corporation) with an excitation filter of $510 \mathrm{~nm}$ (Brightline Fluorescence Filter). An emission filter of $610 \mathrm{~nm}$ [610FG01-50(T257), Andover Corporation] was used before the emitted light was recorded using a MiCam Ultima CMOS Lcamera (SciMedia), sampling at a rate of $1 \mathrm{kHz}$. Images were captured on a $100 \times 100$ array with an inter-pixel resolution of $0.1 \mathrm{~mm}$.

CV was calculated as previously described (George et al., 2015) using an algorithm by Bayly et al. (1998). Briefly, maximum rate of optical action potential rise at each pixel was calculated to determine activation time. A parabolic surface was fit to activation times to determine vectors for $\mathrm{CV}$ at each pixel. CV was quantified in two directions, longitudinal and transverse $\left(\mathrm{CV}_{\mathrm{L}}\right.$ and $\mathrm{CV}_{\mathrm{T}}$, respectively), with anisotropic ratio (AR) calculated as $\mathrm{CV}_{\mathrm{L}} / \mathrm{CV}_{\mathrm{T}}$. Conduction in each direction was calculated from a group of vectors that were within 5 pixels and with an angle of $\pm 8^{\circ}$ from direction of longitudinal (fastest) or transverse (slowest) propagation. The first vectors immediately adjacent to the site of pacing were excluded to reduce pacing artifacts in the $\mathrm{CV}$ analysis. $\mathrm{CV}$ was only quantified up to 32 pixels from the site of pacing in the longitudinal direction and 16 pixels in the transverse direction to reduce the contribution of conduction breakthrough. Longitudinal CV was only quantified if there were at least 10 vectors meeting the criteria above and transverse $\mathrm{CV}$ was quantified if at least 50 vectors met the criteria above.

Rise time (RT) was calculated by the time difference from 20 to $80 \%$ of the peak fluorescent action potential amplitude during depolarization. RT was calculated both in the longitudinal $\left(\mathrm{RT}_{\mathrm{L}}\right)$ and transverse $\left(\mathrm{RT}_{\mathrm{T}}\right)$ directions. Action potential duration (APD) was calculated as the difference between the activation time and $85 \%$ repolarization from peak action potential amplitude.

\section{Western Blotting}

Hearts $(n=3)$, perfused with respective solutions for $30 \mathrm{~min}$, were snap frozen. Tissue was homogenized in a RIPA lysis buffer $(50 \mathrm{mM}$ Tris pH 7.4, $150 \mathrm{mM} \mathrm{NaCl}, 1 \mathrm{mM}$ EDTA, $1 \%$ Triton X-100, $1 \%$ sodium deoxycholate, $2 \mathrm{mM} \mathrm{NaF}, 200 \mu \mathrm{M}$ Na3VO4) supplemented with HALT Protease and Phosphatase Inhibitor Cocktail (ThermoScientific). Following sonication and clarification by centrifugation, the BioRad DC protein assay was employed to determine and normalize protein concentrations prior to analysis. SDS-PAGE electrophoresis was performed as previously described using 4-20\% NuPage Bis-Tris or 3-8\% TrisAcetate gels (Life Technologies) which were then transferred using the Trans-Blot Turbo system (BioRad) to low-fluorescence PVDF membrane and blocked with 5\% BSA in TNT buffer (0.1\% Tween 20, 150mM NaCl, 50mM Tris $\mathrm{pH} 8.0)$ for $1 \mathrm{~h}$ at room temperature. Membranes were then incubated with rabbit anti-phospho-Cx43 ${ }^{\operatorname{Ser} 368}$ (1:1000 in 5\% BSA TNT, \#3511 Cell Signaling Technology) overnight at $4{ }^{\circ} \mathrm{C}$. Following several washes in TNT, secondary detection was performed using goat anti-rabbit HRP antibody (1:5000, abcam) for $1 \mathrm{~h}$ at room temperature. Bound antibody was detected post washing using Clarity Western ECL Substrate (BioRad) and imaged using the BioRad Chemidoc MP system. Membranes were then stripped with Re-Blot Plus Strong (Millipore) according to manufacturer's instructions. To detect total Cx43, stripped membranes were blocked for $1 \mathrm{~h}$ at room temperature in 5\% milk in TNT buffer, and subsequently incubated overnight at $4{ }^{\circ} \mathrm{C}$ with primary antibodies against Cx43 (1:4000, C6219 rabbit, Sigma Aldrich), and alpha-tubulin (1:4000, T6199 mouse, Sigma-Aldrich) diluted in 5\% milk TNT. Membranes were then washed and incubated with the fluorescently distinct secondary antibodies goat antimouse AlexaFluor555 and goat anti-rabbit AlexaFlour647 (both 1:1000 in milk TNT, Life Technologies) for $1 \mathrm{~h}$ at room temperature. Following several washes in TNT, membranes were fixed in methanol, dried, and imaged using the Biorad Chemidoc 
MP System. Protein expression was quantified by densitometry using ImageLab software (BioRad), Cx43 expression levels were normalized to alpha-tubulin, and Cx43 phosphorylate Serine 368 (Cx43-p368S) to total Cx43.

\section{Statistics Analysis}

Statistical analysis was performed using a two tailed Student's $t$-test for both paired and unpaired data. A $p \leq 0.025$ after Bonferrroni correction was considered significant. All values are reported as mean \pm standard error unless otherwise noted.

\section{RESULTS}

\section{Conduction Velocity-Control Conditions ( $0 \mu$ M Carbenoxolone)}

Cardiac conduction was quantified from guinea pig ventricles to determine whether increasing $\left[\mathrm{K}^{+}\right]_{\mathrm{o}}$ and decreasing $\left[\mathrm{Na}^{+}\right]_{\mathrm{o}}$ produced similar effects in ex vivo guinea pig as it did in mice hearts (George et al., 2015). Representative epicardial isochrones in Figure 1A demonstrate the effect of solution composition on the spatial extent of epicardial activation at both 300 and $160 \mathrm{~ms}$ BCL. These maps suggest that cardiac conduction under control conditions was similar when hearts were perfused with Solution A or B. Further, representative isochrones maps suggest that reducing BCL decreases $C_{\mathrm{L}}$ and $\mathrm{CV}_{\mathrm{T}}$, consistent with sodium channel restitution kinetics (Allouis et al., 2006). Representative action potential upstrokes in Figure 1B from equally spaced sites demonstrate slower $\mathrm{CV}_{\mathrm{T}}$ than $\mathrm{CV}_{\mathrm{L}}$ as evidenced by increased temporal separation between action potential upstrokes in the transverse direction.

Reducing BCL significantly decreased $\mathrm{CV}_{\mathrm{L}}$ for both Solutions $A$ and $B$ (Figure 1C). Interestingly, reducing BCL to $160 \mathrm{~ms}$ with Solution A did not decrease $\mathrm{CV}_{\mathrm{T}}$, although a trend was observed ( $p=0.03$ ). On the other hand, changing BCL with Solution $\mathrm{B}$ caused a significant decrease in $\mathrm{CV}_{\mathrm{T}}$. For all experiments, solution composition did not significantly change $\mathrm{CV}_{\mathrm{L}}$ or $\mathrm{CV}_{\mathrm{T}}$ under control conditions (Figure 1D). These data suggest that solution composition does not significantly modulate conduction dependence on pacing rate with normal GJ coupling, because both solutions changed CV similarly under all conditions.

\section{Conduction Velocity-15 $\mu \mathrm{M}$ Carbenoxolone}

We previously demonstrated that GJ inhibition with $15 \mu \mathrm{M}$ CBX does not significantly alter CV (Veeraraghavan et al., 2012). For Solution $A+15 \mu \mathrm{M}$ CBX, reducing BCL to $160 \mathrm{~ms}$ significantly decreased $\mathrm{CV}_{\mathrm{L}}$ but did not significantly decrease $\mathrm{CV}_{\mathrm{T}}$ (Figure 2A). Under these conditions the relationship did not trend toward significance $(p=0.70)$ in contrast to control.

Similar to control, reducing BCL from 300 to $160 \mathrm{~ms}$ still decreased $\mathrm{CV}_{\mathrm{L}}$ and $\mathrm{CV}_{\mathrm{T}}$ in hearts perfused with Solution $\mathrm{B}$ (Figure 2A). Importantly, comparing $\mathrm{CV}_{\mathrm{L}}$ and $\mathrm{CV}_{\mathrm{T}}$ for Solutions $\mathrm{A}$ and $\mathrm{B}$ did not reveal conduction differences when hearts were perfused with $15 \mu \mathrm{M}$ CBX at either pacing rate (Figure 2B), and this is similar to findings under control conditions. These data suggest that solution composition

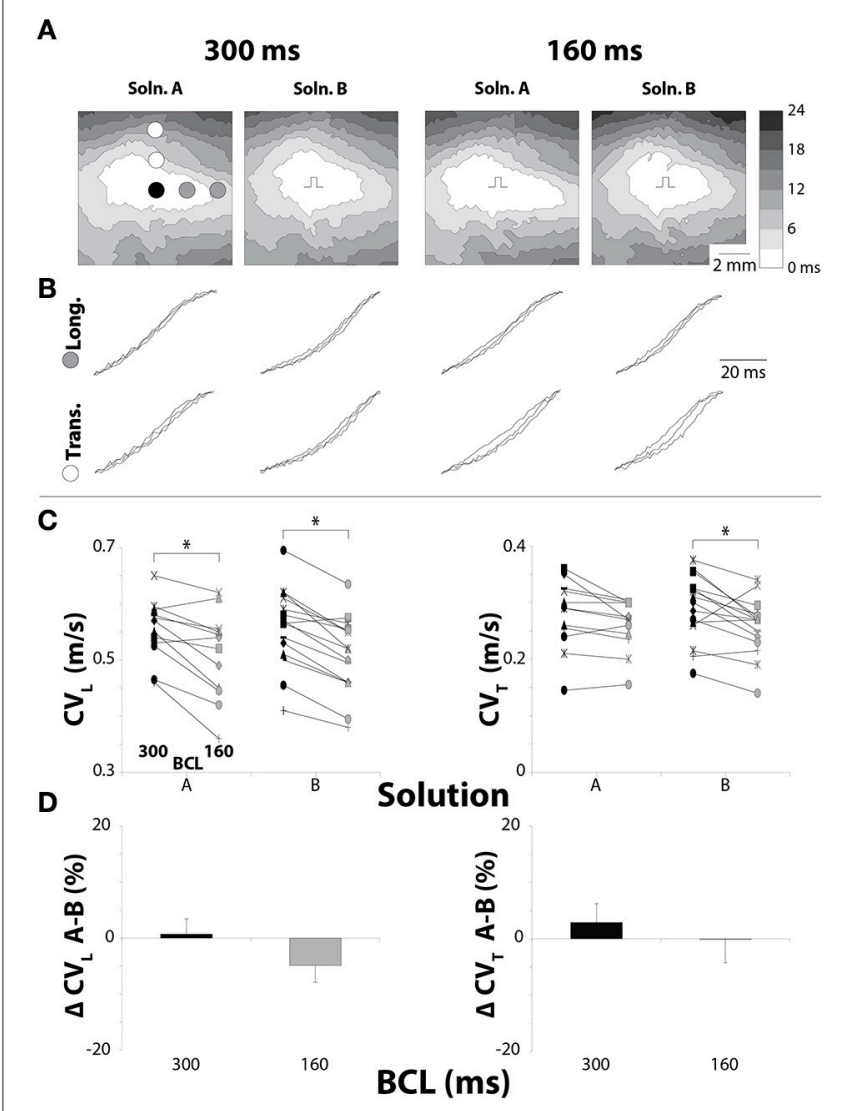

FIGURE 1 | Pacing rate but not solution composition alters $\mathrm{CV}$ in hearts with normal GJ coupling. (A) Representative isochrones from hearts perfused without $\mathrm{CBX}$, showing conduction slowing between pacing rates, but not solutions. (B) Uniformly spaced action potential upstrokes from the same hearts as pictured in (A), demonstrating temporal upstroke separation as another indicator of decreased CV. (C) Black symbols: 300 ms BCL, Gray symbols: $160 \mathrm{~ms}$ BCL. CV measurements for longitudinal and transverse directions. CV decreased due to increased pacing rate for each combination except Solution $A$ in the transverse direction. (D) Percent changes in $C_{L}$ and $\mathrm{CV}_{\mathrm{T}}$ between Solutions $\mathrm{A}$ and $\mathrm{B}$ show no changes in $\mathrm{CV}$ due to perfusate. ${ }^{*} p<0.025$ between pacing rates.

does not significantly modulate conduction dependence on pacing rate when a GJ uncoupler does not measurably slow conduction.

\section{Conduction Velocity-30 $\mu \mathrm{M}$ Carbenoxolone}

Next, we increased CBX to $30 \mu \mathrm{M}$ since it has been previously demonstrated that CBX between 20 and $100 \mu \mathrm{M}$ can slow cardiac conduction (Spray et al., 2006). For Solution A + $30 \mu \mathrm{M} \mathrm{CBX,}$ reducing $B C L$ from 300 to $160 \mathrm{~ms}$ did not significantly decrease $\mathrm{CV}_{\mathrm{L}}$ but it did decrease $\mathrm{CV}_{\mathrm{T}}$ (Figure $3 \mathrm{~A}$ ).

Similar to control and $15 \mu \mathrm{M} \mathrm{CBX}, \mathrm{CV}_{\mathrm{L}}$ and $\mathrm{CV}_{\mathrm{T}}$ significantly decreased when BCL was reduced to $160 \mathrm{~ms}$ in hearts perfused with Solution B $+30 \mu \mathrm{M}$ CBX (Figure 3A). Thus, rapid pacing, in hearts perfused with Solution B, decreased CV in both the longitudinal and transverse direction for all degrees of GJ 


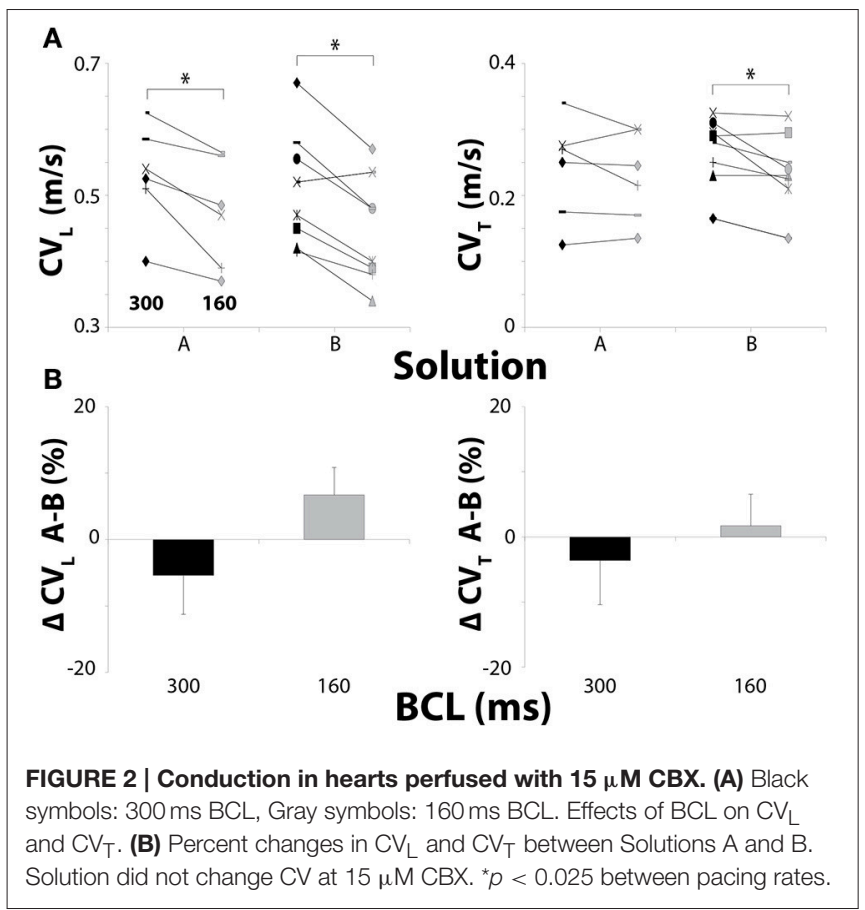

uncoupling, whereas the same was not true for hearts perfused with Solution A.

Similar to conditions above, the change in $\mathrm{CV}_{\mathrm{L}}$ and $\mathrm{CV}_{\mathrm{T}}$ between Solutions A and B were not significant at $300 \mathrm{~ms}$ BCL (Figure 3B) with $30 \mu \mathrm{M}$ CBX. However, Solution B decreased $\mathrm{CV}_{\mathrm{L}}$ and $\mathrm{CV}_{\mathrm{T}}$ significantly more than Solution A at $160 \mathrm{~ms}$ BCL (Figure 3B, $\dagger$ ). These data demonstrate that significant GJ uncoupling can exacerbate $\mathrm{CV}$ dependent differences on $\left[\mathrm{K}^{+}\right]_{\mathrm{o}}$ and $\left[\mathrm{Na}^{+}\right]_{\mathrm{o}}$ when pacing rate is increased.

\section{Perinexal Width}

The perinexus is defined as the extracellular microdomain immediately adjacent to GJ plaques, and these microdomains, rich in the cardiac isoform of the voltage gated sodium channel, have been proposed as the structural unit of a cardiac ephapse (Rhett et al., 2013; George et al., 2015; Veeraraghavan et al., 2015). Using transmission electron microscopy, the perinexus was quantified from hearts perfused with Solution A, Solution A $+\mathrm{CBX} 30 \mu \mathrm{M}$, and Solution B + CBX $30 \mu \mathrm{M}$ (Figure 4A). The yellow shaded region in the images represents the first $150 \mathrm{~nm}$ of the perinexus adjacent to a GJ plaque. The intermembrane widths of perinexi were measured in $5 \mathrm{~nm}$ increments for the first $15 \mathrm{~nm}$ and then in $15 \mathrm{~nm}$ intervals up to150 nm away from the GJ (Figure 4B). Perinexal width was significantly larger with Solution A alone when compared to tissue perfused with CBX (Solution A or B). With CBX, there were no significant differences in perinexal width between Solutions A and B as summarized in Figure 4C. The data also demonstrates that the perinexal width from 60 to $105 \mathrm{~nm}$ is reduced by CBX independent of solution composition. Therefore, the difference in CV observed between Solutions A and B at $30 \mu \mathrm{M}$ CBX is not likely related to solution induced perinexal differences.

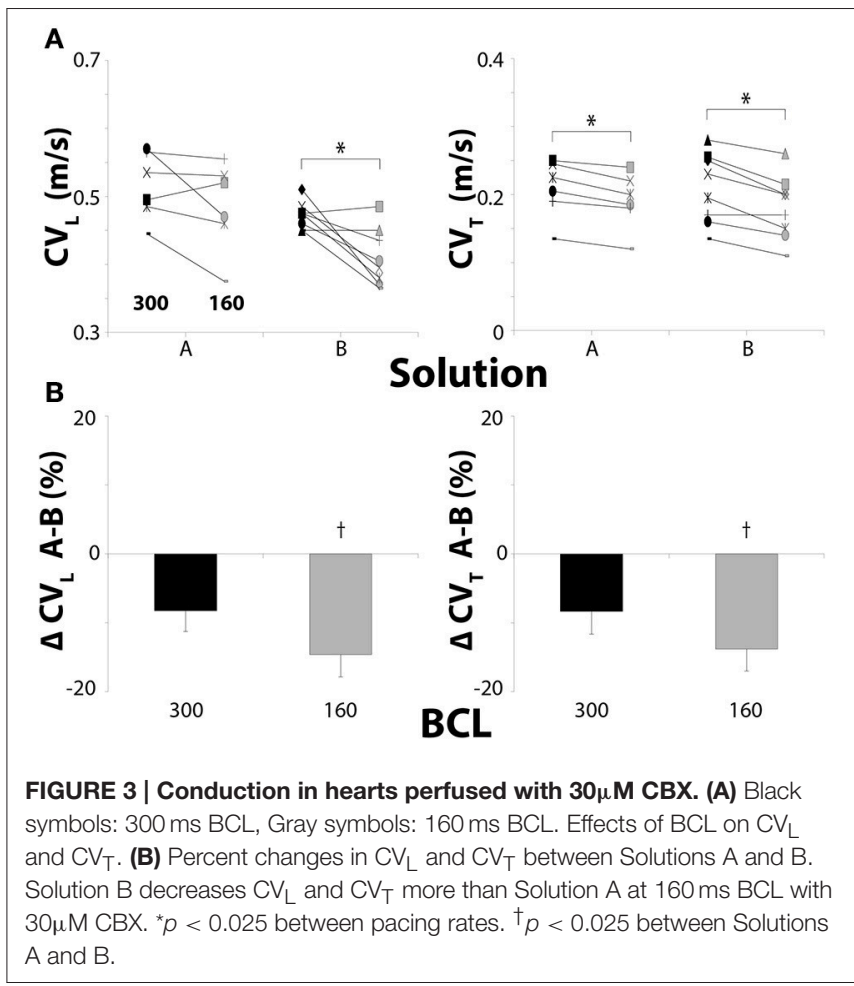

\section{Cx43 Expression}

Many studies have demonstrated that $\mathrm{CV}$ is dependent on ionic perfusate composition (Kishida et al., 1979; Kagiyama et al., 1982; Pressler et al., 1982). We sought to determine whether the reported changes in perfusate composition can also alter Cx43 expression. Expression levels of total and Cx43p368S were measured using alpha-tubulin as a protein loading control in hearts perfused for $30 \mathrm{~min}$ with Solution A or B. Figures 5A,B demonstrate that solution composition did not alter total $\mathrm{Cx} 43$ expression. Dephosphorylation at serine 368 leads to a cascade which internalizes Cx43 in cardiac cells (Smyth et al., 2014), and Cx43-p368S protein levels are often quantified as a correlate of non-functional Cx43 GJs (Hund et al., 2007; Palatinus et al., 2011). Importantly, Cx43-p368S expression levels were not different in preparations perfused with Solution A or B (Figures 5C,D). In a separate set of experiments, Cx43-p368S was compared to total $\mathrm{Cx} 43$ in hearts perfused with Solutions A or $\mathrm{B}$, and freshly explanted hearts, revealing that perfusion did not alter the ratio of phosphorylated Cx43 (Supplemental Figure 1). These data suggest that solution associated conduction changes were not predominantly due to $\mathrm{Cx} 43$ expression changes.

\section{Action Potential Duration}

APD during perfusion of Solution B was shorter than in hearts perfused with Solution A for all CBX concentrations and BCLs (Figure 6, $\dagger$ ). As expected, APD significantly shortened with both solutions when BCL was reduced from 300 to $160 \mathrm{~ms}$ (Figure 6, *). Since APD shortened approximately equally with Solutions A and B, and the magnitude of APD shortening was similar, these data suggest that APD restitution kinetics may not 

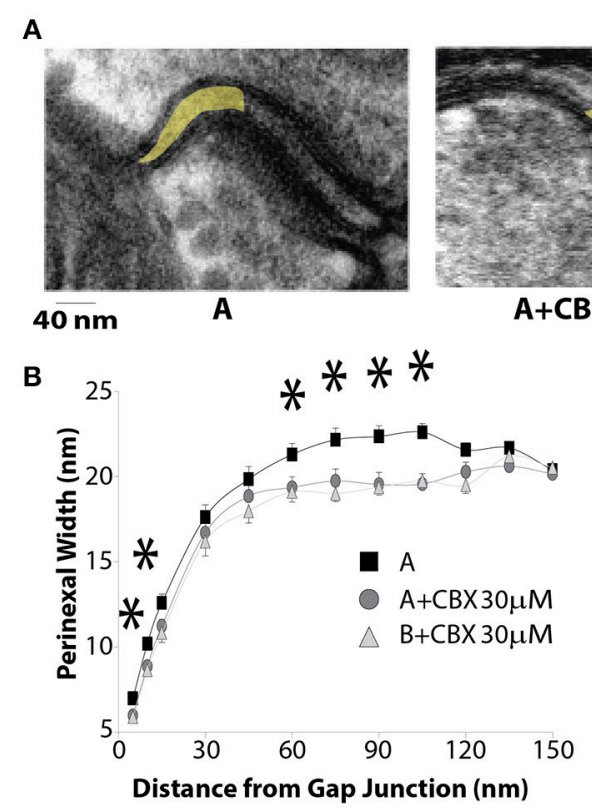

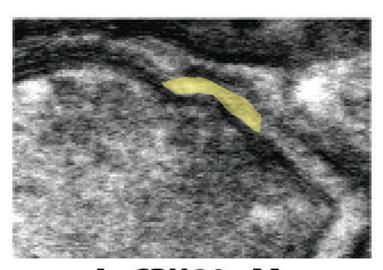

$\mathrm{A}+\mathrm{CBX} 30 \mu \mathrm{M}$

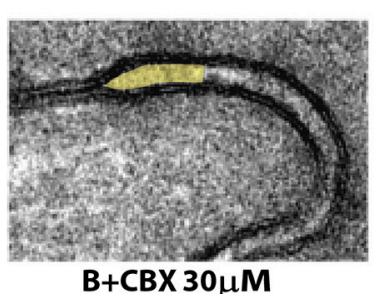

$\mathrm{B}+\mathrm{CBX} 30 \mu \mathrm{M}$

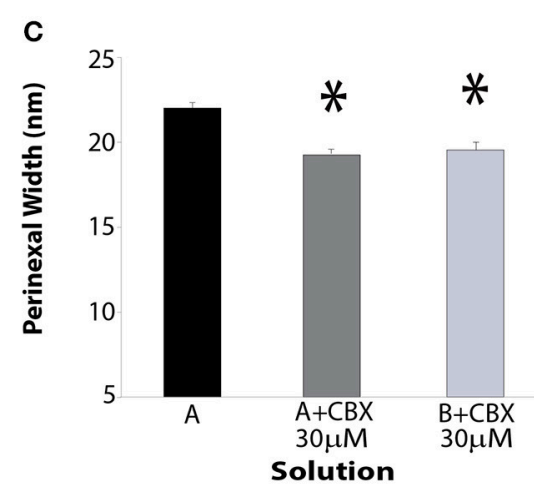

FIGURE 4 | CBX decreases perinexal width. (A) Representative transmission electron microscopy images of the edge of a GJ plaque and the perinexus (highlighted in yellow). (B) Perinexal width as a function of distance from the GJ plaque. CBX decreases intercellular separation between 60 and $105 \mathrm{~nm}$ from the GJ. (C) Summary Data between 60 and $105 \mathrm{~nm}$ from the GJ plaque. ${ }^{*} p<0.025$ from Solution A.

explain the changes in $\mathrm{CV}$ reported above. In fact, one might expect that Solution A, which produced the longer APD, would decrease $\mathrm{CV}$ more at a $160 \mathrm{~ms} \mathrm{BCL}$, and this was not the case.

\section{Rise Time}

Optical rise time (RT) has been previously used as an inverse correlate of cellular excitability (Spach et al., 1981; Poelzing and Rosenbaum, 2004; Poelzing et al., 2004). Importantly, $15 \mu \mathrm{M}$ CBX did not significantly alter RT relative to control (Figure 7). With $30 \mu \mathrm{M}$ CBX however, RT significantly increased (Figure 7, $\dagger)$. In contrast, solution composition did not significantly alter RT. Altering pacing rate also did not significantly change RT in either the longitudinal $\left(\mathrm{RT}_{\mathrm{L}}\right)$ or transverse $\left(\mathrm{RT}_{\mathrm{T}}\right)$ directions of propagation.

\section{DISCUSSION}

The data demonstrate how varying $\left[\mathrm{K}^{+}\right]_{\mathrm{o}},\left[\mathrm{Na}^{+}\right]_{\mathrm{o}}$, and pacing rate modulates conduction sensitivity to pharmacologic GJ inhibition in guinea pig ventricular preparations. Previous studies have demonstrated that each of these factors can affect $\mathrm{CV}$ individually, but that small combined changes in these parameters can lead to relatively significant emergent effects on conduction (Buchanan et al., 1985; de Groot et al., 2003; George et al., 2015; Veeraraghavan et al., 2015). The present study is consistent with these finding and supports a hypothesis that small differences in artificial blood substitute solutions do not produce significant electrophysiological differences with normal GJ coupling. However, when GJ coupling is reduced, extracellular ionic composition and heart rate have important effects on cardiac conduction.

\section{Effects of $\left[\mathrm{K}^{+}\right]_{\mathrm{o}}$ and $\left[\mathrm{Na}^{+}\right]_{\circ}$}

The relationship between $\mathrm{CV}$ and $\left[\mathrm{K}^{+}\right]_{\mathrm{o}}$ is biphasic. Specifically, in guinea pig, it was demonstrated that $\mathrm{CV}$ is maximal around $8 \mathrm{mM}\left[\mathrm{K}^{+}\right]_{\mathrm{o}}$ (Kagiyama et al., 1982; Buchanan et al., 1985; Veenstra et al., 1987; Nygren and Giles, 2000). Interestingly, increasing $\left[\mathrm{K}^{+}\right]_{\mathrm{o}}$ from $4.6 \mathrm{mM}$ in Solution $\mathrm{A}$ to $7.0 \mathrm{mM}$ with Solution B, did not alter CV during control conditions or $15 \mu \mathrm{M}$ $\mathrm{CBX}$, which is unexpected based on previous works when $\left[\mathrm{K}^{+}\right]_{\mathrm{o}}$ was altered in a similar range (Kagiyama et al., 1982; Buchanan et al., 1985). One important difference between this and previous studies is that $\left[\mathrm{Na}^{+}\right]_{0}$ is reduced in Solution B relative to A. The results show that $\mathrm{CV}$ is relatively insensitive to the changes in $\left[\mathrm{K}^{+}\right]_{\mathrm{o}}$ and $\left[\mathrm{Na}^{+}\right]_{\mathrm{o}}$ during normal and presumably low GJ uncoupling $(15 \mu \mathrm{M} \mathrm{CBX})$, with increased sensitivity at $30 \mu \mathrm{M}$ $\mathrm{CBX}$. These results are consistent with our data obtained in mice with narrow perinexal widths and presumably increased EpC (George et al., 2015).

The finding that increasing $\left[\mathrm{K}^{+}\right]_{\mathrm{o}}$ in guinea pig myocardium can slow conduction is consistent with the study of Pandit et al. who found that dominant rotor frequencies are decreased, suggesting slowed conduction, when $\left[\mathrm{K}^{+}\right]_{\mathrm{o}}$ is increased from 4 to $7 \mathrm{mM}$ (Pandit et al., 2010). The intriguing finding that increasing $\left[\mathrm{K}^{+}\right]_{\mathrm{o}}$ in ventricular myocardium can increase $\mathrm{CV}$ under certain conditions and decrease it under others is an important future direction for research since increased $\left[\mathrm{K}^{+}\right]_{\mathrm{o}}$ is critically important to understanding electrical abnormalities in diseases such as cardiac ischemia (Kagiyama et al., 1982; Buchanan et al., 1985). Ischemia is also acutely associated with acutely increased heart rate and collapse of the extracellular space, and on a relatively longer time scale, loss of GJ coupling, (Janse and Wit, 1989; Kostin et al., 2003; Severs et al., 2004) 

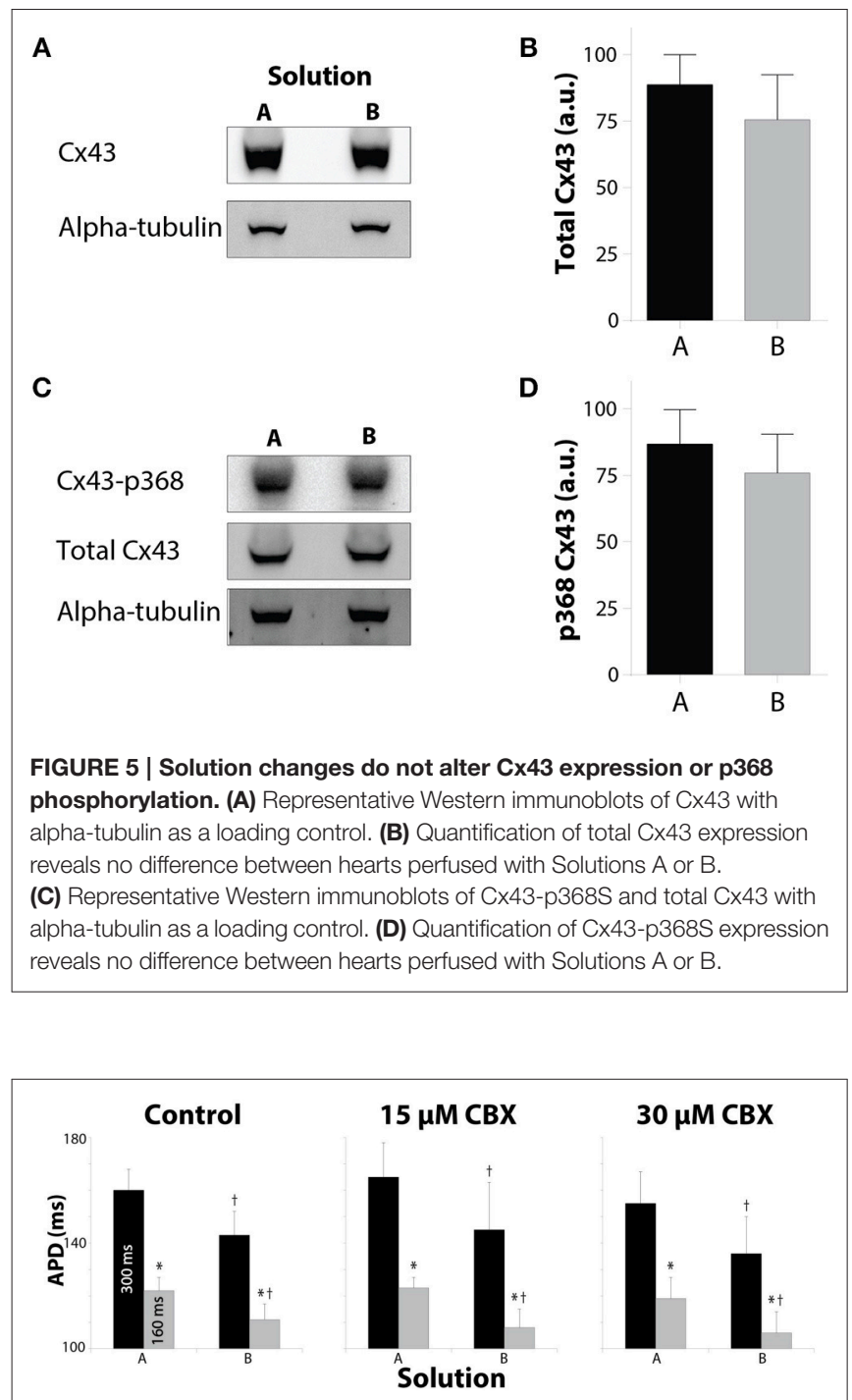

FIGURE 6 | Action potential duration measurements for all solution and pacing rate combinations tested. Reducing $B C L$ always shortened APD for all solutions at every $\mathrm{CBX}$ concentration. ${ }^{*} p<0.025$ between $\mathrm{BCL}$. Solution B significantly shortened APD relative to Solution A for all CBX concentrations. $\dagger_{p}<0.025$ between Solutions.

further highlighting the importance of understanding these diverse modulators of cardiac conduction.

Increasing $\left[\mathrm{K}^{+}\right]_{\mathrm{o}}$ and $\left[\mathrm{Na}^{+}\right]_{\mathrm{o}}$ have both been associated with changes in ion channel kinetics. During hypokalemia for example, peak current density of the inward rectifier potassium current $\left(\mathrm{I}_{\mathrm{K} 1}\right)$ is reduced, the slow component of the delayed rectifier potassium current $\left(\mathrm{I}_{\mathrm{Ks}}\right)$ is increased, and the rapid component of the delayed rectifier potassium current $\left(\mathrm{I}_{\mathrm{Kr}}\right)$ is decreased (Scamps and Carmeliet, 1989; Sanguinetti and Jurkiewicz, 1992). Additionally, co-transporters such as the Na$\mathrm{K}$ pump can be activated through a combination of $\left[\mathrm{Na}^{+}\right]_{i}$ and $\left[\mathrm{K}^{+}\right]_{\mathrm{o}}$ (Gadsby, 1984; Glitsch, 2001). Therefore, future studies will be required to elucidate additional effects of other channels, pumps, and exchangers on cardiac conduction.

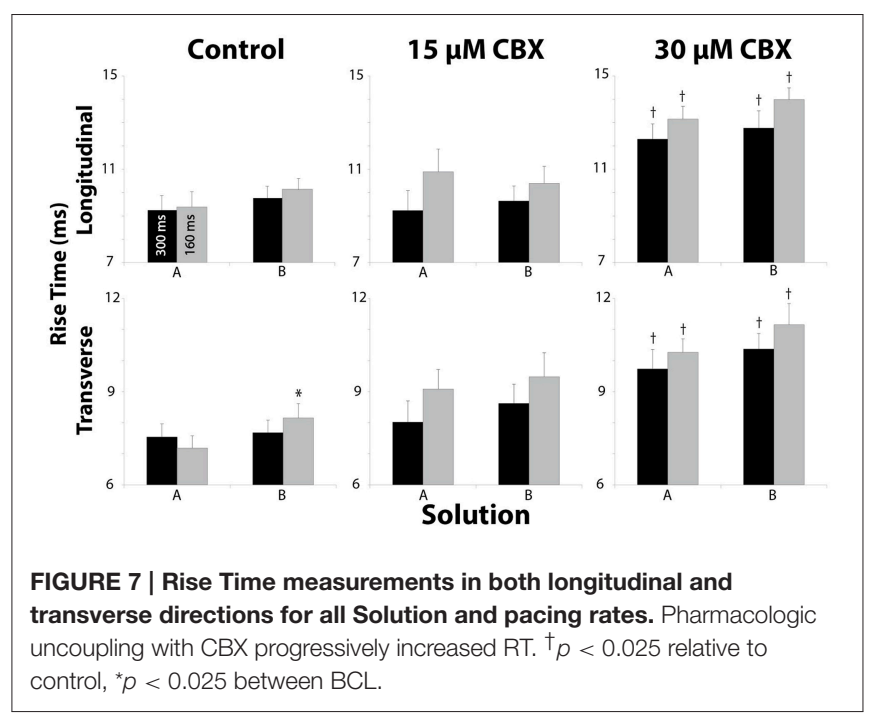

\section{Effects of Pacing Rate}

It is well accepted that $\mathrm{CV}$ decreases when pacing rate increases, due to sodium channel inactivation (Allouis et al., 2006; Stein et al., 2011). Here, we demonstrated that reducing BCL decreased CV depending on the solution composition and level of pharmacologic GJ inhibition. Specifically, reducing BCL in hearts perfused with Solution B with and without CBX decreased $\mathrm{CV}_{\mathrm{L}}$ and $\mathrm{CV}_{\mathrm{T}}$. The same effects were not always observed with Solution A. Our previous research suggests that EpC can support normal conduction when GJs are reduced (Veeraraghavan et al., 2012, 2015; George et al., 2015). The finding that Solution A is less sensitive to GJ uncoupling, suggests that Solution A may promote EpC by maintaining sodium channel availability (lower $\left.\left[\mathrm{K}^{+}\right]_{\mathrm{o}}\right)$ and increasing sodium driving force $\left(\left[\mathrm{Na}^{+}\right]_{\mathrm{o}}\right)$. Further, even greater sodium channel inactivation by rapid pacing does not significantly decrease CV even with GJ uncoupling sufficient to reduce $\mathrm{CV}$.

\section{Effects of Gap Junctional Coupling}

In the current study, increasing the concentration of CBX appeared to progressively decrease CV. This agrees with previous research which demonstrated that concentrations as high as $15 \mu \mathrm{M}$ CBX do not significantly decrease CV, while concentrations between 20 and $100 \mu \mathrm{M}$ CBX can decrease CV (Spray et al., 2006; Veeraraghavan et al., 2012, 2015). According to previous research, the IC50 of GJ inhibition by CBX is between 50 and $100 \mu \mathrm{M}$ (Ye et al., 2003; Bruzzone et al., 2005; Spray et al., 2006; Suadicani et al., 2006). The observation that a significant $\mathrm{CV}$ decrease secondary to CBX can be modulated by solution composition and cardiac hydration further suggests that using conduction velocity to estimate IC50 of CBX may be complicated by alternative modes of conduction.

It is also possible that ionic differences in solutions altered Cx43 functional expression. However, the lack of a significant total or Cx43-p368S change in $\mathrm{Cx} 43$ expression suggests, but does not prove, that reported results are not due to GJ remodeling. 


\section{Effects on Rise Time}

Previous studies suggest that $\mathrm{I}_{\mathrm{Na}}$ correlates with $\mathrm{CV}$ and that the maximal rate of action potential upstroke rise $\left(\mathrm{dV} / \mathrm{dt}_{\max }\right)$ is a correlate of peak $\mathrm{I}_{\mathrm{Na}}$. This is supported by studies which demonstrated that decreasing $\mathrm{I}_{\mathrm{Na} \text {, max }}$ can decrease $\mathrm{dV} / \mathrm{dt}_{\max }$ and CV (Shaw and Rudy, 1997). Optical RT is an inverse correlate of $\mathrm{dV} / \mathrm{dt}_{\max }$ (Spach et al., 1981; Poelzing and Rosenbaum, 2004; Poelzing et al., 2004). The theory of cardiac conduction reserve during GJ uncoupling suggests that RT should first decrease during GJ uncoupling without a measurable effect on cardiac conduction (Rudy and Quan, 1987; Cole et al., 1988; Shaw and Rudy, 1997). We never observed such a relationship. In short, RT either did not change with GJ uncoupling by CBX or it increased, and this is consistent with other similar studies (Jalife et al., 1989; Rohr et al., 1998). However, it is important to note that CBX is a pharmacologic GJ uncoupler with off target effects, and this may explain a lack of agreement with theoretical predictions.

\section{Effects on Perinexal Width}

Our group previously demonstrated that changing bulk interstitial volume can modulate CV (Veeraraghavan et al., 2012, 2015). We also demonstrated that CV is inversely correlated to perinexal width (George et al., 2015; Veeraraghavan et al., 2015). In other words, increasing perinexal width can decrease ventricular CV. To our knowledge, this is the first demonstration that $\mathrm{CBX}$ can decrease perinexal width, which from previous work should increase CV. An important difference in this study compared to our previous manuscripts (Veeraraghavan et al., 2012; George et al., 2015) is that changes in perinexal width in this study were caused by pharmacological intervention with CBX, instead of mannitol or altered calcium concentrations. As changes in perinexal width due to CBX have never been previously reported, it is difficult to discuss the mechanistic link between perinexal width and CBX since this was also not explored in this study. However, the relationship between CBX and perinexal width may be related to a study by Goldberg et al. demonstrating that glycyrrhetinic acid derivatives disrupt gap junction plaques (Goldberg et al., 1996), which could alter the structure of the perinexus. Therefore, these results suggest that $15 \mu \mathrm{M}$ CBX may promote EpC while simultaneously reducing GJ coupling. By this mechanism, modest levels of CBX GJ uncoupling may not alter CV.

\section{Limitations}

This study relies entirely upon using pacing protocols as well as pharmacological GJ inhibitors. However, the findings that altering $\left[\mathrm{Na}^{+}\right]_{\mathrm{o}}$ and $\left[\mathrm{K}^{+}\right]_{\mathrm{o}}$ can modulate cardiac conduction with pharmacologic inhibition is similar to findings in mice heterozygous null for Cx43 (George et al., 2015). It will be interesting to know in the future whether connexin targeting peptides behave similarly to glycerhetinic acid derivatives.

It is well established that the electromechanical uncoupler BDM can affect cardiac conduction, and may have therefore confounded the results here. While this possibility cannot be excluded, BDM was present for each experiment, and all electrophysiologic comparisons were paired. However, perinexal measurements were analyzed in an unpaired fashion, and BDM may have altered these results. Yet, we previously demonstrated that BDM does not change perinexal width relative to freshly excised hearts (Veeraraghavan et al., 2015).

It has been shown that $\mathrm{Cx} 43$ localization can change due to cardiac disease (Spragg et al., 2005; Spragg and Kass, 2006; Duffy, 2012). While we provide evidence that perinexal spacing was only changed for samples that included CBX, alteration of $\mathrm{Cx} 43$ localization could account for some of the electrophysiological changes that were seen. However, the effects quantified in this study occurred in 10 or less minutes and were independent of perfusion order. Therefore, it seems unlikely that $\mathrm{Cx} 43$ cellular expression patterns were significantly altered on this time scale.

The mechanisms that underlie this atypical conduction response to perfusate composition during GJ uncoupling could be due to either altered cellular excitability (Kléber et al., $1987 a, b)$ around the entire myocyte or ephaptic mechanisms (Veeraraghavan et al., 2012, 2015; George et al., 2015). Importantly, the finding that conduction slowing secondary to GJ uncoupling can be exacerbated by relatively small changes in extracellular ions suggests that the mechanism governing the CVGJ relationship is very sensitive to ionic perturbations within the physiologic range, and this warrants additional investigation.

\section{CONCLUSIONS}

We present evidence that altering $\left[\mathrm{K}^{+}\right]_{\mathrm{o}},\left[\mathrm{Na}^{+}\right]_{\mathrm{o}}$, and heart rate have important effects on GJ mediated conduction slowing. The magnitude of ionic changes, while small, were in accordance with the original hypothesis that the changes in $\left[\mathrm{K}^{+}\right]_{\mathrm{o}}$ and $\left[\mathrm{Na}^{+}\right]_{\mathrm{o}}$ would not substantially alter $\mathrm{CV}$ as previously demonstrated in mice with normal Cx43 expression levels, but GJ uncoupling can produce solution dependent CV changes. The implications of this study are that relatively small physiologic changes in extracellular ionic composition do not significantly perturb cardiac electrophysiology under "normal" conditions, but these same changes may have significant effects during cardiac stress as a result of GJ remodeling or increased heart rate.

\section{AUTHOR CONTRIBUTIONS}

All authors are fully aware of the content of the manuscript and have contributed to its writing. ME and SP were responsible for the entire direction of the project. SG was responsible for the design of the solution fluids and the TEM imaging. MZ was responsible for the immunoblotting, analysis and reporting of $\mathrm{Cx} 43$. JS was responsible for supervising and the immunoblotting, analysis and reporting of $\mathrm{Cx} 43$.

\section{FUNDING}

This work was supported by an R01-HL102298 awarded to SP, and a VTCRI Medical Research Scholar Award to ME.

\section{SUPPLEMENTARY MATERIAL}

The Supplementary Material for this article can be found online at: http://journal.frontiersin.org/article/10.3389/fphys. 2016.00016 


\section{REFERENCES}

Akar, F. G., Laurita, K. R., and Rosenbaum, D. S. (2000). Cellular basis for dispersion of repolarization underlying reentrant arrhythmias. J. Electrocardiol. 33(Suppl.), 23-31. doi: 10.1054/jelc.2000.20313

Allouis, M., Le Bouffant, F., Wilders, R., Peroz, D., Schott, J. J., Noireaud, J., et al. (2006). 14-3-3 is a regulator of the cardiac voltage-gated sodium channel Nav1.5. Circ. Res. 98, 1538-1546. doi: 10.1161/01.RES.0000229244.97 $497.2 \mathrm{c}$

Anastassiou, C. A., Perin, R., Markram, H., and Koch, C. (2011). Ephaptic coupling of cortical neurons. Nat. Neurosci. 14, 217-223. doi: 10.1038/nn.2727

Bayly, P. V., KenKnight, B. H., Rogers, J. M., Hillsley, R. E., Ideker, R. E., and Smith, W. M. (1998). Estimation of conduction velocity vector fields from epicardial mapping data. IEEE Trans. Biomed. Eng. 45, 563-571. doi: 10.1109/10.668746

Bokil, H., Laaris, N., Blinder, K., Ennis, M., and Keller, A. (2001). Ephaptic interactions in the mammalian olfactory system. J. Neurosci. 21, RC173.

Bruzzone, R., Barbe, M. T., Jakob, N. J., and Monyer, H. (2005). Pharmacological properties of homomeric and heteromeric pannexin hemichannels expressed in Xenopus oocytes. J. Neurochem. 92, 1033-1043. doi: 10.1111/j.14714159.2004.02947.x

Buchanan, J. W. Jr., Saito, T., and Gettes, L. S. (1985). The effects of antiarrhythmic drugs, stimulation frequency, and potassium-induced resting membrane potential changes on conduction velocity and $d V / d t m a x$ in guinea pig myocardium. Circ. Res. 56, 696-703. doi: 10.1161/01.RES.56. 5.696

Cole, W. C., Picone, J. B., and Sperelakis, N. (1988). Gap junction uncoupling and discontinuous propagation in the heart. A comparison of experimental data with computer simulations. Biophys. J. 53, 809-818. doi: 10.1016/S00063495(88)83160-6

de Groot, J. R., Veenstra, T., Verkerk, A. O., Wilders, R., Smits, J. P., Wilms-Schopman, F. J., et al. (2003). Conduction slowing by the gap junctional uncoupler carbenoxolone. Cardiovasc. Res. 60, 288-297. doi: 10.1016/j.cardiores.2003.07.004

Duffy, H. S. (2012). The molecular mechanisms of gap junction remodeling. Heart Rhythm 9, 1331-1334. doi: 10.1016/j.hrthm.2011.11.048

Gadsby, D. C. (1984). The Na/K pump of cardiac cells. Annu. Rev. Biophys. Bioeng. 13, 373-398. doi: 10.1146/annurev.bb.13.060184.002105

George, S. A., Sciuto, K. J., Lin, J., Salama, M. E., Keener, J. P., Gourdie, R. G., et al. (2015). Extracellular sodium and potassium levels modulate cardiac conduction in mice heterozygous null for the Connexin 43 gene. Pflugers Arch. 467, 2287-2297. doi: 10.1007/s00424-015-1698-0

Girouard, S. D., Pastore, J. M., Laurita, K. R., Gregory, K. W., and Rosenbaum, D. S. (1996). Optical mapping in a new guinea pig model of ventricular tachycardia reveals mechanisms for multiple wavelengths in a single reentrant circuit. Circulation 93, 603-613. doi: 10.1161/01.CIR.93.3.603

Glitsch, H. G. (2001). Electrophysiology of the sodium-potassium-ATPase in cardiac cells. Physiol. Rev. 81, 1791-1826.

Goldberg, G. S., Moreno, A. P., Bechberger, J. F., Hearn, S. S., Shivers, R. R., MacPhee, D. J., et al. (1996). Evidence that disruption of connexon particle arrangements in gap junction plaques is associated with inhibition of gap junctional communication by a glycyrrhetinic acid derivative. Exp. Cell Res. 222, 48-53. doi: 10.1006/excr.1996.0006

Hand, P. E., and Peskin, C. S. (2010). Homogenization of an electrophysiological model for a strand of cardiac myocytes with gap-junctional and electricfield coupling. Bull. Math. Biol. 72, 1408-1424. doi: 10.1007/s11538-0099499-2

Hund, T. J., Lerner, D. L., Yamada, K. A., Schuessler, R. B., and Saffitz, J. E. (2007). Protein kinase Cepsilon mediates salutary effects on electrical coupling induced by ischemic preconditioning. Heart Rhythm 4, 1183-1193. doi: 10.1016/j.hrthm.2007.05.030

Jalife, J., Sicouri, S., Delmar, M., and Michaels, D. C. (1989). Electrical uncoupling and impulse propagation in isolated sheep Purkinje fibers. Am. J. Physiol. 257, H179-H189.

Janse, M. J., and Wit, A. L. (1989). Electrophysiological mechanisms of ventricular arrhythmias resulting from myocardial ischemia and infarction. Physiol. Rev. 69, 1049-1169.

Kagiyama, Y., Hill, J. L., and Gettes, L. S. (1982). Interaction of acidosis and increased extracellular potassium on action potential characteristics and conduction in guinea pig ventricular muscle. Circ. Res. 51, 614-623. doi: 10.1161/01.RES.51.5.614

Kishida, H., Surawicz, B., and Fu, L. T. (1979). Effects of K+ and K+induced polarization on $(\mathrm{dV} / \mathrm{dt}) \mathrm{max}$, threshold potential, and membrane input resistance in guinea pig and cat ventricular myocardium. Circ. Res. 44, 800-814. doi: 10.1161/01.RES.44.6.800

Kléber, A. G., Riegger, C. B., and Janse, M. J. (1987a). Electrical uncoupling and increase of extracellular resistance after induction of ischemia in isolated, arterially perfused rabbit papillary muscle. Circ. Res. 61, 271-279. doi: 10.1161/01.RES.61.2.271

Kléber, A. G., Riegger, C. B., and Janse, M. J. (1987b). Extracellular K+ and $\mathrm{H}+$ shifts in early ischemia: mechanisms and relation to changes in impulse propagation. J. Mol. Cell. Cardiol. 19(Suppl. 5), 35-44. doi: 10.1016/S00222828(87)80608-9

Kostin, S., Rieger, M., Dammer, S., Hein, S., Richter, M., Klovekorn, W. P., et al. (2003). Gap junction remodeling and altered connexin 43 expression in the failing human heart. Mol. Cell. Biochem. 242, 135-144. doi: 10.1023/A:1021154115673

Kucera, J. P., Rohr, S., and Rudy, Y. (2002). Localization of sodium channels in intercalated disks modulates cardiac conduction. Circ. Res. 91, 1176-1182. doi: 10.1161/01.RES.0000046237.54156.0A

Lin, J., and Keener, J. P. (2010). Modeling electrical activity of myocardial cells incorporating the effects of ephaptic coupling. Proc. Natl. Acad. Sci. U.S.A. 107, 20935-20940. doi: 10.1073/pnas.1010154107

Lin, J., and Keener, J. P. (2013). Ephaptic coupling in cardiac myocytes. IEEE Trans. Biomed. Eng. 60, 576-582. doi: 10.1109/TBME.2012.2226720

Lin, J., and Keener, J. P. (2014). Microdomain effects on transverse cardiac propagation. Biophys. J. 106, 925-931. doi: 10.1016/j.bpj.2013.11.1117

Lou, Q., Li, W., and Efimov, I. R. (2012). The role of dynamic instability and wavelength in arrhythmia maintenance as revealed by panoramic imaging with blebbistatin vs. 2,3-butanedione monoxime. Am. J. Physiol. Heart Circ. Physiol. 302, H262-H269. doi: 10.1152/ajpheart.00711.2011

Maïna, I., Tabi, C. B., Ekobena Fouda, H. P., Mohamadou, A., and Kofane, T. C. (2015). Discrete impulses in ephaptically coupled nerve fibers. Chaos 25, 043118. doi: 10.1063/1.4919077

Mori, Y., Fishman, G. I., and Peskin, C. S. (2008). Ephaptic conduction in a cardiac strand model with 3D electrodiffusion. Proc. Natl. Acad. Sci. U.S.A. 105, 6463-6468. doi: 10.1073/pnas.0801089105

Nygren, A., and Giles, W. R. (2000). Mathematical simulation of slowing of cardiac conduction velocity by elevated extracellular. Ann. Biomed. Eng. 28, 951-957. doi: $10.1114 / 1.1308489$

Palatinus, J. A., Rhett, J. M., and Gourdie, R. G. (2011). Enhanced PKCepsilon mediated phosphorylation of connexin 43 at serine 368 by a carboxyl-terminal mimetic peptide is dependent on injury. Channels (Austin) 5, 236-240. doi: 10.4161/chan.5.3.15834

Pandit, S. V., Warren, M., Mironov, S., Tolkacheva, E. G., Kalifa, J., Berenfeld, O., et al. (2010). Mechanisms underlying the antifibrillatory action of hyperkalemia in Guinea pig hearts. Biophys. J. 98, 2091-2101. doi: 10.1016/j.bpj.2010.02.011

Poelzing, S., Akar, F. G., Baron, E., and Rosenbaum, D. S. (2004). Heterogeneous connexin43 expression produces electrophysiological heterogeneities across ventricular wall. Am. J. Physiol. Heart Circ. Physiol. 286, H2001-H2009. doi: 10.1152/ajpheart.00987.2003

Poelzing, S., and Rosenbaum, D. S. (2004). Altered connexin43 expression produces arrhythmia substrate in heart failure. Am. J. Physiol. Heart Circ. Physiol. 287, H1762-H1770. doi: 10.1152/ajpheart.00346.2004

Pressler, M. L., Elharrar, V., and Bailey, J. C. (1982). Effects of extracellular calcium ions, verapamil, and lanthanum on active and passive properties of canine cardiac purkinje fibers. Circ. Res. 51, 637-651. doi: 10.1161/01.RES.51.5.637

Rhett, J. M., Veeraraghavan, R., Poelzing, S., and Gourdie, R. G. (2013). The perinexus: sign-post on the path to a new model of cardiac conduction? Trends Cardiovasc. Med. 23, 222-228. doi: 10.1016/j.tcm.2012.12.005

Rohr, S., Kucera, J. P., and Kléber, A. G. (1998). Slow conduction in cardiac tissue, I: effects of a reduction of excitability versus a reduction of electrical coupling on microconduction. Circ. Res. 83, 781-794. doi: 10.1161/01.RES. 83.8.781

Rudy, Y., and Quan, W. L. (1987). A model study of the effects of the discrete cellular structure on electrical propagation in cardiac tissue. Circ. Res. 61, 815-823. doi: 10.1161/01.RES.61.6.815 
Sanguinetti, M. C., and Jurkiewicz, N. K. (1992). Role of external Ca2+ and K+ in gating of cardiac delayed rectifier K+ currents. Pflugers Arch. 420, 180-186. doi: 10.1007/BF00374988

Scamps, F., and Carmeliet, E. (1989). Effect of external K+ on the delayed K+ current in single rabbit Purkinje cells. Pflugers Arch. 414(Suppl. 1), S169-S170. doi: 10.1007/BF00582287

Severs, N. J., Coppen, S. R., Dupont, E., Yeh, H. I., Ko, Y. S., and Matsushita, T. (2004). Gap junction alterations in human cardiac disease. Cardiovasc. Res. 62, 368-377. doi: 10.1016/j.cardiores.2003.12.007

Shaw, R. M., and Rudy, Y. (1997). Ionic mechanisms of propagation in cardiac tissue. Roles of the sodium and L-type calcium currents during reduced excitability and decreased gap junction coupling. Circ. Res. 81, 727-741. doi: 10.1161/01.RES.81.5.727

Smyth, J. W., Zhang, S. S., Sanchez, J. M., Lamouille, S., Vogan, J. M., Hesketh, G. G., et al. (2014). A 14-3-3 mode-1 binding motif initiates gap junction internalization during acute cardiac ischemia. Traffic 15, 684-699. doi: $10.1111 /$ tra.12169

Spach, M. S., Miller, W. T. 3rd., Geselowitz, D. B., Barr, R. C., Kootsey, J. M., and Johnson, E. A. (1981). The discontinuous nature of propagation in normal canine cardiac muscle. Evidence for recurrent discontinuities of intracellular resistance that affect the membrane currents. Circ. Res. 48, 39-54. doi: 10.1161/01.RES.48.1.39

Sperelakis, N., and McConnell, K. (2002). Electric field interactions between closely abutting excitable cells. IEEE Eng. Med. Biol. Mag. 21, 77-89. doi: 10.1109/51.993199

Spragg, D. D., Akar, F. G., Helm, R. H., Tunin, R. S., Tomaselli, G. F., and Kass, D. A. (2005). Abnormal conduction and repolarization in late-activated myocardium of dyssynchronously contracting hearts. Cardiovasc. Res. 67, 77-86. doi: 10.1016/j.cardiores.2005.03.008

Spragg, D. D., and Kass, D. A. (2006). Pathobiology of left ventricular dyssynchrony and resynchronization. Prog. Cardiovasc. Dis. 49, 26-41. doi: 10.1016/j.pcad.2006.05.001

Spray, D. C., Ye, Z. C., and Ransom, B. R. (2006). Functional connexin "hemichannels": a critical appraisal. Glia 54, 758-773. doi: 10.1002/glia.20429

Stein, M., van Veen, T. A., Hauer, R. N., de Bakker, J. M., and van Rijen, H. V. (2011). A 50\% reduction of excitability but not of intercellular coupling affects conduction velocity restitution and activation delay in the mouse heart. PLoS ONE6:e20310. doi: 10.1371/journal.pone.0020310

Su, C. Y., Menuz, K., Reisert, J., and Carlson, J. R. (2012). Non-synaptic inhibition between grouped neurons in an olfactory circuit. Nature 492, 66-71. doi: 10.1038 /nature 11712

Suadicani, S. O., Brosnan, C. F., and Scemes, E. (2006). P2X7 receptors mediate ATP release and amplification of astrocytic intercellular $\mathrm{Ca}^{2+}$ signaling. J. Neurosci. 26, 1378-1385. doi: 10.1523/JNEUROSCI.390205.2006

UoM, R. A. R. (2009). Reference Values for Laboratory Animals. Normal Hematology Values. Minneapolis; St. Paul, MN. Available online at: http://www. ahc.umn.edu/rar/refvalues.html

Van der Goes van Naters, W. (2013). Inhibition among olfactory receptor neurons. Front. Hum. Neurosci. 7:690. doi: 10.3389/fnhum.2013.00690

Veenstra, R. D., Joyner, R. W., Wiedmann, R. T., Young, M. L., and Tan, R. C. (1987). Effects of hypoxia, hyperkalemia, and metabolic acidosis on canine subendocardial action potential conduction. Circ. Res. 60, 93-101. doi: 10.1161/01.RES.60.1.93

Veeraraghavan, R., Gourdie, R. G., and Poelzing, S. (2014). Mechanisms of cardiac conduction: a history of revisions. Am. J. Physiol. Heart Circ. Physiol. 306, H619-H627. doi: 10.1152/ajpheart.00760.2013

Veeraraghavan, R., Larsen, A. P., Torres, N. S., Grunnet, M., and Poelzing, S. (2013). Potassium channel activators differentially modulate the effect of sodium channel blockade on cardiac conduction. Acta Physiol. (Oxf). 207, 280-289. doi: 10.1111/j.1748-1716.2012.02481.x

Veeraraghavan, R., Lin, J., Hoeker, G. S., Keener, J. P., Gourdie, R. G., and Poelzing, S. (2015). Sodium channels in the $\mathrm{Cx} 43$ gap junction perinexus may constitute a cardiac ephapse: an experimental and modeling study. Pflugers Arch. 467, 2093-2105. doi: 10.1007/s00424-014-1675-z

Veeraraghavan, R., Salama, M. E., and Poelzing, S. (2012). Interstitial volume modulates the conduction velocity-gap junction relationship. Am. J. Physiol. Heart Circ. Physiol. 302, H278-H286. doi: 10.1152/ajpheart.008 68.2011

Ye, Z. C., Wyeth, M. S., Baltan-Tekkok, S., and Ransom, B. R. (2003). Functional hemichannels in astrocytes: a novel mechanism of glutamate release. J. Neurosci. 23, 3588-3596.

Young, R. C. (2007). Myocytes, myometrium, and uterine contractions. Ann. N. Y. Acad. Sci. 1101, 72-84. doi: 10.1196/annals.1389.038

Conflict of Interest Statement: The authors declare that the research was conducted in the absence of any commercial or financial relationships that could be construed as a potential conflict of interest.

Copyright (C) 2016 Entz, George, Zeitz, Raisch, Smyth and Poelzing. This is an openaccess article distributed under the terms of the Creative Commons Attribution License (CC BY). The use, distribution or reproduction in other forums is permitted, provided the original author(s) or licensor are credited and that the original publication in this journal is cited, in accordance with accepted academic practice. No use, distribution or reproduction is permitted which does not comply with these terms. 